\title{
Renal Functional Changes After Radical Cystectomy in The Early-Mid Term Period
}

\author{
Radikal Sistektomi Sonrası Erken-Orta Dönem Renal Fonksiyonel \\ Değişiklikler
}

\author{
Mehmet Salih Boğa, Mahmut Ekrem İslamoğlu, Selim Taş, Ali Erhan Eren, Kamil Sarac, Eren Erdi \\ AKSARAY, Mutlu Ateş
}

Sağlık Bilimleri Üniversitesi, Antalya Eğitim ve Araştırma Hastanesi, Üroloji Ana Bilim Dalı, Antalya

Dergiye Ulaşma Tarihi: 28.11.2020 Dergiye Kabul Tarihi: 07.12.2020 Doi: 10.5505/aot.2020.13285

\section{ÖZET}

GİRIŞ ve AMAÇ: Mesane tümörü nedeniyle açık radikal sistektomi uygulanan hastaların postoperatif kısa-orta dönemdeki renal fonksiyonlarındaki değişimlerinin değerlendirilmesi.

YÖNTEM ve GEREÇLER: Çalışmada Aralık 2010-Ekim 2019 tarihleri arasında mesane tümörü nedeniyle açık radikal sistektomi uygulanan toplam 76 hastanın, demografik, operatif ve postoperative verileri ile postoperative 1. gün, 1., 3., 6., 9. ve 12. ay renal fonksiyon değerlerinin işlem öncesine göre değişimleri değerlendirildi. Eş zamanlı nefrektomi uygulanan, preoperatif kronik böbrek yetmezliği nedeniyle diyaliz öyküsü bulunan, tek böbrekli olan ve 1 yıldan daha az takipli hastalar çalışmaya dahil edilmedi.

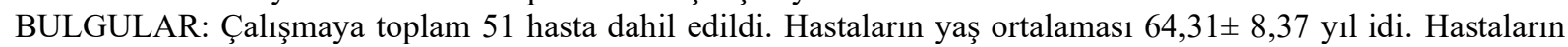
$\%$ 86.3'üne ileal konduit uygulanırken, \%13.7 sine ortotopik mesane uyguland1. Postoperatif renal fonksiyonlar hastaların \%51 sinde düşüş gösterirken, \%49 1nda artış izlendiği ya da değişim izlenmediği tesbit edildi. Preoperatif eGFR $62.70 \pm 23.22 \mathrm{~mL} / \mathrm{min} / 1.73 \mathrm{~m} 2$ iken postoperatif 1-3 gün, 1. ay, 3, ay, 6.ay, 9.ay, 12. ay eGFR değerleri sirasıyla $58.55 \pm 28.08,64.67 \pm 26.52,64.35 \pm 23.23,61.18 \pm 24.80,59.93 \pm 21.99$ ve $58.09 \pm 22.33$ $\mathrm{mL} / \mathrm{min} / 1.73 \mathrm{~m} 2$ şeklinde kaydedildi. İşlem sonrası 1 y1l içinde yapılan periyodik eGFR ölçümlerinde peroperatif erken dönemde nisbeten hızlı eGFR düşüşü izlenirken sonrasında kademeli bir değişim olduğu görüldü.

TARTIŞMA ve SONUÇ: Kas invaziv ve yüksek risk mesane tümörlerinde açık radikal sistektomi sonrası erken dönemde renal fonksiyonlarda ani bozulmalar izlenebilirken sonrasında yakın takip izlemle normal değerlerine yaklaştığı görünmektedir. Morbidite ve mortalitesi yüksek bu prosedür de renal fonksiyonların korunması açısından özellikle postoperatif erken dönemde yakın takip ve izlem önermekteyiz.

Anahtar Kelimeler: Mesane tümörü, radikal sistektomi, ileal konduit, renal fonksiyon, eGFR

\section{ABSTRACT}

INTRODUCTION: To evaluate the postoperative early-mid term renal functions of patients who underwent open radical cystectomy for bladder tumor.

METHODS: In the study, demographic, operative, postoperative data and postoperative 1st day, 1st, 3rd, 6th, 9th and 12th month renal function values of 76 patients who underwent open radical cystectomy due to bladder tumor between December 2010 and October 2019 were evaluated. Patients who underwent concomitant nephrectomy, history of dialysis due to preoperative chronic renal failure, history of solitary kidney and had a follow-up less than 1 year were excluded from the study.

RESULTS: A total of 51 patients were included in the study. The mean age of the patients was $64.31 \pm$ 8.37 years. Ileal conduit was applied to $86.3 \%$ of the patients, while orthotopic bladder was applied to $13.7 \%$. While postoperative renal functions decreased in $51 \%$ of the patients, it was found that there was an increase or no change in $49 \%$ of the patients. While preoperative eGFR was $62.70 \pm 23.22 \mathrm{~mL} / \mathrm{min} / 1.73 \mathrm{~m} 2$, postoperative 1-3 days, $1 \mathrm{st}$ month, 3rd month, 6th month, 9th month, and 12th month eGFR values were $58.55 \pm$ $28.08,64.67 \pm 26.52,64.35 \pm 23.23,61.18 \pm 24.80,59.93 \pm 21.99$ and $58.09 \pm 22.33 \mathrm{~mL} / \mathrm{min} / 1.73 \mathrm{~m} 2$, respectively. While the eGFR levels relatively rapid decrease in the early perioperative period, but a gradual change was observed afterward for the periodic eGFR measurements performed within 1 year after the procedure.

DISCUSSION AND CONCLUSION: The rapid deterioration in renal functions can be observed in the early period in muscle-invasive or high-risk bladder tumors after the open radical cystectomy, but it seems to approach 
normal values with close follow-up. In this procedure with high morbidity and mortality, we recommend close follow-up and care, especially in the early postoperative period, in order to protect renal functions.

Keywords: Bladder tumor, radical cystectomy, ileal conduit, renal function, eGFR

\section{GíRIŞ}

Kas invaziv veya yüksek risk mesane tümörlerinde açık radikal sistektomi ve pelviklenfadenektomi altın standart tedavi yöntemidir (1). Son zamanlarda robotik cerrahi gibi minimal invaziv yöntemler kanama miktarının daha az olması, barsak motilitesi ve buna bağlı hastanede kalış süresinin daha kısa olması ve kozmetik açıdan avantajlar sağlasa da $(2,3)$ pulmoner, kardiyak ve pozisyonel sorunlar nedeniyle robotik cerrahiye uygun olmayan radikal sistektomiye aday hastalar için açık radikal sistektominin şuan olduğu gibi ve gelecektede yerini koruyacağ 1 düşünülmektedir.

Radikal sistektomi ve eş zamanlı üriner diversiyonlarda renal fonksiyonların korunması en önemli hedeftir $(4,5)$. Yapılan çalışmalar radikal sistektomi sonrası hastaların \%5-27 sinde eGFR düşüşü olduğunu göstermektedir $(6,7,8)$. Eisenberg ve ark. iseradikal sistektomi sonras1 1 . ve 10 y1 sonunda hastaların $\% 27$ ve $\% 72$ sinde eGFR düşüşü olduğunu bildirdiler(9).

İşlem sonrası renal fonksiyonlarda bozulma yaş, preoperatif tahmini glomerüler filtrasyon oranı (eGFR/ estimated glomeruler filtration rate), kronik hipertansiyon, diyabet gibi modifiye edilemeyen faktörlere bağlı olabileceği gibi işlem sonrası obstrüksiyon, komplike üriner enfeksiyon gibi önlenebilir faktörlere de bağlı olabilmektedir $(9,10,11)$.

Biz bu çalışmada radikal sitektomi sonrası 12 ay içerisinde renal fonksiyonların belli periyodlar arasında nasıl etkilendiğini göstermeyi planladık.

\section{YÖNTEM VE GEREÇLER}

Çalışma için Aralık 2010 ve Ekim 2019 tarihleri arasinda radikal sistektomi uygulanan toplam 76 hastanın dosya verileri retrospektif olarak tarandi. Eş zamanlı nefrektomi uygulanan, preoperatif kronik böbrek yetmezliği (KBY) nedeniyle diyaliz öyküsü bulunan, tek böbrekli olan ve 1 yıldan daha az takipli hastalar çalışmaya dahil edilmedi. Kriterleri karşılayan toplam 51 hasta çalışmaya dahil edildi.
Radikal sistektomi daha öncesinde tariflenen yönteme uygun olarak yapıldı (1). Radikal sistektomi esnasında hastaya uygulanacak diversiyon tipi tümörün mesane boynu invazyonu, KBY varlığı, gastrointestinal durumu, hastanın tedaviye adaptasyon durumu ve cerrahın seçimine göre karar verildi. Ortotopikdiversiyon için Studer tekniği uygulanıldı(12).Özetle; Studer rezervuar için ileoçekal valvin yaklaşık olarak $20 \mathrm{~cm}$ proksimalinden $50 \mathrm{cmlik}$ ileal segment izole edildikten sonra, ileal uçlar barsak stapleri ile tekrardan uçuca anastomoz edildi. İzole edilen ileal segmentin proksimal $10 \mathrm{~cm}$ lik kısmı baca şeklinde birakıldıktan sonra kalan segment antimezenterik kısımdan detübülerize edildi. Detübülerize segmentin önce posterior ardından anterior kısmı 3.0Vicry ile sferik şekilde kapatıldı. Üretral anastomoz için neobladderin distal antimezenterik kısımdan parmak desteği ile anastomoz deliği açıldı ve 3.0 Monocrylile üretral güdüğe anastomoz edildi. Baca şeklinde ayrilan segment proksimaline üreter distal uçları Bricker tekniği (13) ile anastomoz edildi. Anastomoz tamamlanmadan her iki üretere mono-J stentler konuldu, mono $\mathrm{J}$ stenlerin distal uçları neobladderın antimezenterik kismından çıkartılarak cilt kesi yerinden dışarı alındı. Anastomoz tamamlandıktan sonra kaçak testi uyguland1, kaçak görülen yerlere ek süturlar konuldu, Ilealkonduit için ise ileoçekalvalvin yaklaşık $20 \mathrm{~cm}$ proksimalinden izole edilen 1520 cmlik ileal segmente bilateral üreter distal uçları Bricker (13) veya Wallace (14) yöntemi ile anastomoz edildikten sonra ileal segment distalinin karın sağ alt duvarına ağızlaştırılması şeklinde uygulandı. Kutanöz üroterostomi de ise; sol üreter sigmoid kolonun altından retroperitoneal olarak sağ tarafa alındı ardından sağ üreter ile birlikte daha öncesinde sağ alt abdomen cildi ile ağızlaştırıldı (15). Hastaların tamamına eş zamanlı olarak bilateral pelvik lenf nodu diseksiyonu (PLND) işlemi uyguland. PLND'u daha önce tariflendiği gibi obturator, eksternal iliak, kommon iliak ve presakral bölgeleri içine alacak şekilde uygulandı $(16,17)$.

Çalışmanın birincil amacı radikal sistektomi sonrası 12 aylık sure içerisinde postoperatif 
1.gün, 1, 3, 6, 9 ve 12 aylardaki periyodlarda eGFR değerlerindeki değişimlerini değerlendirmek idi.

Çalışmada renal fonksiyonları değerlendirmek için eGFR değerleri kullanıldı. Çalışmamızda eGFR hesaplamas1 "Modification of Diet in Renal Disease (MDRD): eGFR (mL/min/1.73 $\mathrm{m} 2)=175 \times$ standardized serum creatinine (Scr)-1.154× age-0.203 $\times \quad 1.212$ [siyahiırktansa] $\times 0.742$ [kadınsa]" formula kullanılarak yapıldı (18). Postoperatif eGFR değerlerinde işlem öncesine gore $10 \mathrm{~mL} / \mathrm{min} / 1.73 \quad \mathrm{~m} 2$ azalma renal fonksiyonlarda bozulma olarak tariflendi $(9,19)$.

\section{ISTATISTIKSEL ANALIZ}

İstatistiksel analiz IBM Statistical Package for the Social Sciences soft version 22.0 (IBM SPSS Corp.;Armonk, NY, USA) program1 kullanılarak yapıldı. Değişkenlerin dağılımları analiz edildikten sonra. tanımlayıc istatistikler kullanılarak bulgular elde edildi. Değerler ortalama \pm standart sapma veya sayı (\%) şeklinde belirtildi.

\section{BULGULAR}

Hastaların klinikopatolojik özellikleri ve operatif veriler Tablo 1 ve 2'de özetlenmiştir. Çalışmaya kriterleri sağlayan 51 hasta dahil edildi. Hastaların \%86.3'üne ileal kondüit uygulanırken, \%13.7 sine ortotopik mesane uygulandı. Hastaların \% 51'ine neoadjuvan veya adjuvan kemoterapi uyguland. Hastaların preoperatif hidronefroz oran $1 \% 39.2$ iken, postoperatif hidronefroz oran1 \%23.5 olarak kaydedildi. Takip boyunca hastaların $\% 13.7$ 'sinde komplike üriner enfeksiyon izlendi.

Çalışmaya alınan hastaların işlem öncesi eGFR değerlerine göre \%9.8 i Evre I, \%41.2'si Evre II, \%39.2'si Evre III, \%9.8'i Evre IV şeklindeydi. Preoperatif eGFR 62.70 23.22 $\mathrm{mL} / \mathrm{min} / 1.73 \mathrm{~m} 2$ iken postoperatif $1-3$ gün, 1 . ay, 3. ay, 6.ay, 9. Ay ve 12. ay eGFR değerleri sirasiyla $\quad 58.55 \pm 28.08, \quad 64.67 \pm 26.52$, $64.35 \pm 23.23, \quad 61.18 \pm 24.80, \quad 59.93 \pm 21.99$ ve $58.09 \pm 22.33 \mathrm{~mL} / \mathrm{min} / 1.73 \mathrm{~m}^{2}$ şeklinde tesbit edildi.

Radikal sistektomi sonrası 12. ayda hastaların $\% 51$ inde eGFR değerlerinde düşüş izlenirken \%49unda yükselme izlendi yada değişkenlik izlenmedi. Postoperatif 12. ay da ortalama
eGFR düşüşü $4.22 \pm 33.23 \quad \mathrm{~mL} / \mathrm{min} / 1.73$ $\mathrm{m}^{2}(\% 6.73)$ olarak saptandi. Radikal sistektomi sonras1 12. ayda hastalarin \%27.5inde renal fonksiyonlarında bozulma (eGFR da $>10$ $\mathrm{mL} / \mathrm{min} / 1.73 \mathrm{~m}^{2}$ azalma) saptand 1 .

Hastaların ortalama takip süresi $41.80 \pm 23.14$ ay idi. Takip süresince radikal sistektomi sonrası yeni başlangıçlı kronik böbrek yetmezliği gelişen hasta sayısı $6(\% 11.8)$ idi.

Tablo 1. Hastaların klinikopatolojik özellikleri ve operatif verileri

\begin{tabular}{|c|c|}
\hline Değişkenler & $\begin{array}{l}\text { Açık radikal sistektomi } \\
(\mathrm{n}=51)\end{array}$ \\
\hline $\begin{array}{r}\text { Cinsiyet } \\
\text { Erkek } \\
\text { Kadın } \\
\end{array}$ & $\begin{array}{l}39(76.5 \%) \\
12(23.5 \%)\end{array}$ \\
\hline Yaş, y1l & $64,31 \pm 8,37$ \\
\hline BMI (kg/m2) & $26.97 \pm 1.96$ \\
\hline $\begin{array}{l}\text { Ürinerdiversiyon tipi } \\
\text { Ortotopik mesane } \\
\text { İleal kondüit }\end{array}$ & $\begin{array}{l}7(13.7 \%) \\
44(86.3 \%)\end{array}$ \\
\hline Ortalama operasyon süresi, dakika & $381.86 \pm 53.1$ \\
\hline Hastanede kalış süresi, gün & $14.53 \pm 4.54$ \\
\hline Loj dreni kalış süresi, gün & $11.47 \pm 2.55$ \\
\hline $\begin{array}{l}\text { ASA Skoru } \\
\text { I } \\
\text { II } \\
\text { III } \\
\text { IV }\end{array}$ & $\begin{array}{l}4(7.8 \%) \\
23(45.1 \%) \\
20(39.2 \%) \\
4(7.8 \%)\end{array}$ \\
\hline Çıkartılan lenf nodu sayısı & $21.41 \pm 9.13$ \\
\hline $\begin{array}{l}\text { Spesmen patoloji evresi } \\
0 \\
1 \\
2 \\
3 \\
4\end{array}$ & $\begin{array}{l}6(11.8 \%) \\
5(9.8 \%) \\
14(27.5 \%) \\
17(33.3 \%) \\
9(17.6 \%) \\
\end{array}$ \\
\hline $\begin{array}{l}\text { Lenf nodu pozitifliği } \\
\mathrm{N}- \\
\mathrm{N}+\end{array}$ & $\begin{array}{l}37(72.5 \%) \\
14(27.5 \%)\end{array}$ \\
\hline $\begin{array}{l}\text { Cerrahi sınır pozitifliği } \\
\text { Negatif } \\
\text { Positif }\end{array}$ & $\begin{array}{l}48(94.1 \%) \\
3(5.9 \%)\end{array}$ \\
\hline $\begin{array}{l}\text { Kemoterapi } \\
\text { Neoadjuvan } \\
\text { Adjuvan }\end{array}$ & $\begin{array}{l}5(9.8 \%) \\
21(41.2 \%)\end{array}$ \\
\hline $\begin{array}{l}\text { Komplikasyon oranları } \\
\text { Minor (Clavien 1-2) } \\
\text { Major ( Clavien 3-5) }\end{array}$ & $\begin{array}{l}29(56.9 \%) \\
3(5.9 \%)\end{array}$ \\
\hline
\end{tabular}


Tablo 2.Renal fonksiyon değişimlerive renal fonksiyonları etkileyebilecek ek hastalık verileri

\begin{tabular}{|c|c|}
\hline Değişkenler & $\begin{array}{l}\text { Açık } \\
\text { radikal } \\
\text { sistektomi } \\
(\mathrm{n}=51)\end{array}$ \\
\hline $\begin{array}{l}\text { Ek Hastalik } \\
\text { Diyabet } \\
\text { Kronik hipertansiyon }\end{array}$ & $\begin{array}{l}11(21.6 \%) \\
35(68.6 \%)\end{array}$ \\
\hline $\begin{array}{l}\text { PreoperatifeGFRevreleri } \\
\text { I } \\
\text { II } \\
\text { III } \\
\text { IV }\end{array}$ & $\begin{array}{l}5(9.8 \%) \\
21(41.2 \%) \\
20(39.2 \%) \\
5(9.8 \%)\end{array}$ \\
\hline eGFR (preoperatif), $\mathrm{mL} / \mathrm{min} / 1.73 \mathrm{~m}^{2}$ & $\begin{array}{l}62.70 \pm \\
23.22\end{array}$ \\
\hline $\begin{array}{l}\text { eGFR (postoperatif } \\
\text { 1.gün), } \mathrm{mL} / \mathrm{min} / 1.73 \mathrm{~m}^{2}\end{array}$ & $58.55 \pm 28.08$ \\
\hline $\begin{array}{l}\text { eGFR (postoperatif 1. ay), } \\
\mathrm{mL} / \mathrm{min} / 1.73 \mathrm{~m}^{2}\end{array}$ & $64.67 \pm 26.52$ \\
\hline $\begin{array}{l}\text { eGFR (postoperatif 3. ay), } \\
\mathrm{mL} / \mathrm{min} / 1.73 \mathrm{~m}^{2}\end{array}$ & $64.35 \pm 23.23$ \\
\hline $\begin{array}{l}\text { eGFR (postoperatif 6. ay), } \\
\mathrm{mL} / \mathrm{min} / 1.73 \mathrm{~m}^{2}\end{array}$ & $61.18 \pm 24.80$ \\
\hline $\begin{array}{l}\text { eGFR (postoperatif 9. ay), } \\
\mathrm{mL} / \mathrm{min} / 1.73 \mathrm{~m}^{2}\end{array}$ & $59.93 \pm 21.99$ \\
\hline $\begin{array}{l}\text { eGFR (postoperatif 1. y1l), } \\
\mathrm{mL} / \mathrm{min} / 1.73 \mathrm{~m}^{2}\end{array}$ & $\begin{array}{l}58.09 \pm \\
22.33\end{array}$ \\
\hline $\begin{array}{l}\text { 1. y1l sonunda ortalama } \\
\text { eGFRdeğişimi, } \mathrm{mL} / \mathrm{min} / 1.73 \mathrm{~m}^{2}\end{array}$ & $-4.22 \pm 33.23$ \\
\hline eGFR $>10 \mathrm{~mL} / \mathrm{min} / 1.73 \mathrm{~m}^{2}$ düşme & $14(27.5 \%)$ \\
\hline $\begin{array}{l}\text { eGFR değişim } \\
\text { Azalan } \\
\text { Artan veya Değişmeyen }\end{array}$ & $\begin{array}{l}26(51.0 \%) \\
25(49.0 \%)\end{array}$ \\
\hline Preoperatifhidronefroz & $20(39.2 \%)$ \\
\hline Postoperatifhidronefroz & $12(23.5 \%)$ \\
\hline $\begin{array}{l}\text { Takip süresince komplikeüriner } \\
\text { enfeksiyon }\end{array}$ & $7(13.7 \%)$ \\
\hline Yeni başlangıçlı KBY & $6(11.8 \%)$ \\
\hline Ortalama takip süresi, ay & $\begin{array}{l}41.80 \\
\pm 23.14\end{array}$ \\
\hline
\end{tabular}

\section{TARTIŞMA}

Radikal sistektomi yakın takip ve izlem gerektiren yüksek mortalite ve morbiditeye sahip bir prosedürdür $(20,21)$. Üriner diversiyonda temel amaç renal fonksiyonların korunmasıdır. İdeal bir diversiyonun renal fonksiyonları koruması için düşük basınç altında yeterli idrar depolama kapasitesine sahip olmas1 gerekmektedir (22).

Radikal sistektomiyle ilgili olarak onkolojik, yaşam kalitesi ve cinsel fonksiyon gibi bir takım fonksiyonel sonuçları değerlendiren çalışma sayısı literatürde yaygın şekilde mevcut olsa da, renal fonksiyonlardaki bozulmayı periyodik aralıklarla gösteren yayın sayısı hala kısıtlı sayıdadır.

Renal fonksiyonlarda y1llik olarak 1 $\mathrm{mL} / \mathrm{min} / 1.73 \mathrm{~m}^{2}$ l1k düşüş normal olarak Kabul edilmekte iken (23) temel alınan değere (baseline) göre $10 \mathrm{~mL} / \mathrm{min} / 1.73 \mathrm{~m}^{2}$ birim veya $>25 \%$ düşüş renal fonksiyonlarda bozulma olarak tanımlanmaktadır $(9,19,24)$.

Eisenberg ve ark.10 y1l takipli radikal sistektomi serilerinde cerrahiden 1 y1l sonraki ortalama eGFR düşüşünü $5 \mathrm{~mL} / \mathrm{min} / 1.73 \mathrm{~m} 2$ olarak bildirdiler. Renal fonksiyonlarda bozulmayı eGFR da $10 \mathrm{~mL} / \mathrm{min} / 1.73 \mathrm{~m} 2$ 'den daha fazla gerileme olarak tarifledikleri çalışmalarında, ileal konduitlerde renal fonksiyonlarda bozulm aoranını \%26 iken, kontinen diversiyonlarda ise \%31 olarak bildirdiler. Yaş, preoperative eGFR, kronik hipertansiyon, postoperative hidronefroz, piyelonefrit ve üreteroenterik darlık eGFR düşüşünde risk faktörü olarak belirtildi (9).

Al Hussein Al Awamlhve ark.35 ay takipli radikal sistektomi hastalarında diversiyona bağlı komplikasyonlar ve uzun dönem renal fonksiyonlardaki değişimi araştırdıkları çalışmalarında takip süresince ortalama eGFR düşüşünü $14.6 \mathrm{~mL} / \mathrm{min} / 1.73 \mathrm{~m} 2$ olarak bildirdiler. Renal fonksiyonlarda bozulmayı eGFR da $>10 \mathrm{ml} / \mathrm{min} / 1.73 \mathrm{~m} 2$ azalma ve kronik böbrek yetmezliği evresinde ilerleme olarak tarifledikleri çalışmalarında radikal sistektomi sonras1 1.y1lda diversiyon tipine göre renal fonksiyonlarda bozulma oranlarını $\% 20$ ile $\% 24$ olarak bildirdiler(19).

Hamidi ve ark. Kas invaziv mesane tümörü hastalarında farklı tedavi modalitelerinin uzun dönem renal fonksiyonlara olan etkisini karşılaştırdıkları çalışmalarında 1 . Yı1 sonunda radikal sistektomi sonrası eGFR değerinde 4.7 $\mathrm{mL} / \mathrm{min} / 1.73 \mathrm{~m} 2 \quad(\% 5.1)$ düşüş bildirdiler. Multivariant lojistik regresyon analizinde üreteroenterik anastomoz darlı $\breve{g} 1$, baseline eGFR düşüklügü, multimodal tedavi

Adress for correspondence: Varlık, Kazım Karabekir Cd., 07100 Muratpaşa/antalya 07100 Antalya - Türkiye 
uygulamas1, diyabet ve hipertansiyon varlığ 1 5.y1l sonunda eGFR değerinin 60 ve 45 $\mathrm{mL} / \mathrm{min} / 1.73 \mathrm{~m}^{2}$ 'nin altında olmasıyla ilişkili olduğunu bildirdiler (11).

Bizim çalışmamızda radikal sistektomi sonrası 1. y1lda eGFR düşüşü $4.22 \pm 33.23 \mathrm{~mL} / \mathrm{min} / 1.73$ m2(\%6.73) olarak saptandı. Çalışmamızda renal fonksiyonlarda bozulma eGFRda işlem öncesine göre $10 \mathrm{~mL} / \mathrm{min} / 1.73 \mathrm{~m} 2$ lik azalma olarak baz alındığında, radikal sistektomi sonrası 1.yılda renal fonksiyonları bozulan hasta oran1 literatürde bildirilen oranlara benzer sekilde \%27.5 olarak tesbit edildi. Postoperatif dönemde yeni başlangıçlı kronik böbrek yetmezliği gelişen hasta oranı $\% 11.8$ idi.

Yapmış olduğumuz çalışmada postoperative erken dönemde eGFR değerlerinde nisbeten ani düşüş izlenirken sonraki takiplerinde kademeli olarak normal değerlere yaklaştığ izlenmektedir. Mesane tümörünün ureteral orifis tutulumlarına bağlı preoperative eGFR değerlerinde düşüş izlenen hastaların ise postoperative dönemde eGFR değerlerinde artış olduğu gözlendi.

Radikal sistektomi mortalite ve morbididesi yüksek bir cerrahi olup elde ettiğimiz veriler göz önünde bulundurulduğunda renal fonksiyonların korunması için perioperatif yakın izlem ve takip gerektirmektedir. İşlemden hemen sonra eGFR değerlerindeki nisbeten oluşan ani düşüşün, operasyon süresinin uzun olması, hem üriner sistem hem gastrointestinal sistem manuplasyonlarına bağlı vücut sıv1 dengesinin ameliyat sonrası erken dönemde yeterince sağlanamamasına bağlı olduğunu düşünmekteyiz.

Çalışmamızda bir takım kısıtlayıcı etmenler mevcuttu. Bunlardan ilki, çalışmamızın retrospektif olmasıdır. Bunun yanında diğer kısıtlayıcı faktörlerimiz çalışmamızda takip sonunda rekürrens oranlarının olmamasi, yaşam kalitesi, cinsel fonksiyon değerlendirmesi gibi diğer fonksiyonel değerlendirmelerinin olmaması ve takip süresinin literatüre göre nisbeten daha kısa olmasiydi.

\section{SONUÇ}

Açık radikal sistektomikas invaziv veya yüksek risk mesane tümörlerinde operatif ve onkolojik güvenilirliğinin yanında kısa ve orta dönemde renalfonksyonların korunmasında da etkin bir tedavi yöntemi olarak güvenli bir yöntemdir. Her ne kadar minimal invaziv yöntemler hızlı şekilde gelişim gösterse de açık radikal sistektominin uzun bir süre daha güncelliğini koruyacağ düşünülmektedir.

\section{REFERANSLAR}

1. Huang G.J.,Stein J.P. Open radical cystectomy with lymphadenectomy remains the treatment of choice for invasive bladder cancer. Current opinion in urology, 2007. 17(5), 369-375.

2. Nix J, Smith A, Kurpad R, Nielsen ME, Wallen EM, Pruthi RS. Prospective randomized controlled trial of robotic versus open radical cystectomy for bladder cancer: perioperative and pathologic results. EurUrol 2010; 57: 196 - 201

3. Boga MS, Ates M. Timing of lymphadenectomy during robot-assisted radical cystectomy: before or after cystectomy? Fifteen cases with totally intracorporeal urinary diversions. Videosurgery and Other Miniinvasive Techniques. 2020;15(4):596-601. doi:10.5114/wiitm.2020.93793.

4. Kristjansson, A., Wallin, L., \&Månsson, W. (1995). Renal function up to 16 years after conduit (refluxing or anti-reflux anastomosis) or continent urinary diversion. 1. Glomerular filtration rate and patency of uretero-intestinal anastomosis. British journal of urology, 76(5), 539-545.

5. Canter D, Viterbo R, Kutikov A, et al. Baseline renal function status limits patient eligibility to receive perioperative chemotherapy for invasive bladder cancer and is minimally affected by radical cystectomy. Urology 2011; 77: 160-5.

6. Madersbacher S, Schmidt J, Eberle JM, Thoeny HC, Burkhard F, Hochreiter W, et al. Long-term outcome of ileal conduit diversion. J Urol. 2003 Mar; 169(3):98590.doi: 10.1097/01.ju.0000051462.45388.14.

7. Yang WJ, Cho KS, Rha KH et al: Long-term effects of ileal conduit urinary diversion on upperurinary tract in bladder cancer. Urology 2006; 68: 324.

8. Thoeny HC, Sonnenschein MJ, Madersbacher S et al: Is ilealorthotopic bladder substitution with an afferent tubular segment detrimental to the upper urinary tract in the long term? J Urol 2002; 168: 2030.

9. Eisenberg MS, Thompson RH, Frank I, et al. Long-term renal function outcomes after radical cystectomy. J. Urol. 2014; 191: 619-25.

10. Gondo, T., Ohno, Y., Nakashima, J., Hashimoto, T., Nakagami, Y., \& Tachibana, M. (2017). Preoperative determinant of early postoperative renal function following radical cystectomy and intestinal urinary diversion. International urology and nephrology, 49(2), 233-238.

11. Hamidi N, Suer E, Ozkidik M, Gokce MI, Ozturk E, Ozcan C, et al. Effect of Treatment Modality on Long Term Renal Functions in Patients With Muscle Invasive Bladder Cancer. Urol J. 2019 Jun 17;16(3):274-278. doi: 10.22037/uj.v0i0.4251.

12. Studer UE, Turner WH. The ilealorthotopic bladder. Urology 1995; 45: 185-9. 
13. Wallace DM. Ureteric diversion using a conduit: a simplified technique. Br J Urol 1966; 38(5):522-7.

14. Bricker EM. Bladder substitution after pelvic evisceration. SurgClin North Am 1950; 30(5):1511-21.

15. Lusuardi L, Lodde M, Pycha A. Cutaneous ureterostomy. BJU Int 2005;96:1149-59.

16. Bi L, Huang H, Fan $X$, Li K, Xu K, Jiang C, et al. Extended versus non- extended pelvic lymph node dissection and their influence on recurrence- free survival in patients undergoing radical cystectomy for bladder cancer: a systematic review and meta- analysis of comparative studies. BJU Int 2014;113:E39-E48

17. Boğa MS, Özsoy Ç, Aktaş Y, Aydın A, Savaş M, Ateș M. Single-center experience of robot-assisted radical cystectomy (RARC) and extended pelvic lymph node dissection. Turk J Urol. 2020 Mar 14;46(4):288-96.

18. Levey AS, Coresh J, Greene T, Stevens LA, Zhang YL, Hendriksen $\mathrm{S}$, et al. Using standardized serum creatinine values in the modification of diet in renal disease study equation for estimating glomerular filtration rate. Ann Intern Med 2006;145(4):247-54.

19. Al Hussein Al Awamlh, B., Wang, L. C., Nguyen, D. P., Rieken, M., Lee, R. K., Lee, D. J., ...\&Scherr, D. S. (2015). Is continent cutaneous urinary diversion a suitable alternative to orthotopic bladder substitute and ileal conduit after cystectomy? BJU international, 116(5), 805-814.

20. Shabsigh A, Korets R, Vora $\mathrm{KC}$ et al: Defining early morbidity of radical cystectomy for patients with bladder cancer using a standardized reporting methodology. EurUrol 2009; 55: 164.

21. Shimko MS, Tollefson MK, Umbreit EC et al:Long-term complications of conduit urinary diversion. J Urol 2011; 185: 562.

22. Fontaine E, Leaver R, Woodhouse CRJ. The effect of intestinal urinary reservoirs on renal function: a 10-year follow-up. BJU Int 2000;86:195-8.

23. Granerus G, Aurell M. Reference values for 51Cr EDTA clearance as a measure of glomerular filtration rate. Scand J Clin Lab Invest 1981; 41: 611-6.

24. Kristjansson, A., Wallin, L., \&Månsson, W. (1995). Renal function up to 16 years after conduit (refluxing or anti-reflux anastomosis) or continent urinary diversion. 1. Glomerular filtration rate and patency of uretero-intestinal anastomosis. British journal of urology, 76(5), 539-545. 